\title{
Significance of Formal \& Informal Education in Disaster Prevention, Preparedness \& Mitigation
}

\author{
Deepa Gupta ${ }^{1 *}$ and Ruchi Rami Patil ${ }^{2}$ \\ ${ }^{1}$ DRS Research \& Consulting, USA \\ ${ }^{2} J N E C$ College, Aurangabad, India \\ *Corresponding author: Deepa Gupta, DRS Research \& Consulting, Marysville, Ohio, USA
}

Submission: 侮 February 20, 2018; Published: 海 March 12, 2018

\section{Introduction}

Disasters related to weather are increasing day-by-day across the world. Since 2000, over 1 million people worldwide have died from natural disasters, with the cost of damage estimated at over $\$ 1.7$ trillion [1]. Since 2004 there has been a number of massively destructive events. At the end of 2004, the Asian Boxing Day tsunami killed approximately 230,000 people across 14 countries. The 2010 floods in Pakistan directly affected around 20 million people, and have continued to displace substantial numbers each year. In regard to drought, during 2011 and 2012, more than 12 million people in the Horn of Africa were severely affected in what has been called the worst drought in 60 years. According to WHO, 2016 the Ebola outbreak in West Africa, beginning in March 2014, led to 11,310 deaths across Liberia, Sierra Leone and Guinea [2].

Disasters lead to causalities; damages property, essential services, basic infrastructure and means of livelihood. They shatter the normal capacity of the affected community to manage unfavorable and unfortunate situations themselves. In such circumstances the poor section of the society mostly gets affected and becomes vulnerable. The socio-economic backwardness, coupled with lack of skills to respond to disasters increases their vulnerability. Ultimately, it affects negatively to their ability to respond and recover from periodic and intense disasters. Education plays a powerful role in combating disasters. Knowledge related to disasters would not only reduce causalities but also help to prepare and prevent future disasters. Hence, education in Disaster Management is a proactive approach towards disasters. Disaster Management covers a broad range of interventions undertaken before, during and after a disaster to prevent or minimize loss of life, property, minimize human suffering and expedite recovery. Over the past century, disaster management has undergone a substantive change in the composition, nature and policy such as shifting from relief and response mode, to the issues of early warning system, forecasting and monitoring setup for various disasters.

\subsection{Formal and informal education}

Formal education system is the hierarchically structured, graded system, which runs from Primary School through the
University, as well as a variety of specialized programmes and institutions for full time technical and professional training. It caters to the people who can afford to be a part of this system. On the other hand, Informal education system is a lifelong process whereby every individual acquire attitudes, values, skills and knowledge from daily experiences. They gain informative influences from family, neighbors, work, play, and market places. It occurs in an out of school setting which provides base and motivation for further activity and learning. It not only creates awareness in children but also their parents and community at large. It doesn't provide any prescribed framework or curriculum for the learning, but driven by informal conversation; exploring and enlarging experience, and can take place in setting. Other than government agencies; NGOs, research organizations and international donor agencies are actively involved in imparting knowledge related to disaster management and risk reduction to people. Specific tools/approaches that can be used for imparting informal education include:

A. Publications such as posters, guidelines, flyers, brochures, booklets, activity books, paper models, comic books, story books, colouring books, assembly kits and teacher resources.

B. Curricula, modules and presentations such as teacher briefings and community training.

C. E-learning; a self-study curricula.

D. Performing and cultural arts such as plays, dances, poems, songs, street theatre, puppet theatre and engaging local folk troupes.

E. Games and competitions such as card games, board games, cooperative, activities role play, drawing competitions, writing competitions, tournaments and radio quizzes.

F. Audio and video materials such as short videos, radio programmes and television programmes.

G. Web pages and activities such as websites, online games and online quizzes.

H. Social media and telecommunications such as SMS and early warning [3]. 


\section{Case Study: Disaster Management Education in India}

India is a country with diverse geography and climate. More than 58.6 per cent of the landmass is prone to earthquakes of moderate to very high intensity; over 40 million hectares (12 per cent) of its land is prone to floods and river erosion; close to $5,700 \mathrm{kms}$, out of the $7,516 \mathrm{kms}$ long coastline is prone to cyclones and tsunamis; $68 \%$ of its cultivable area is vulnerable to droughts; and, its hilly areas are at risk from landslides and avalanches [4]. During the last thirty years' time span the country has been hit by 431 major disasters resulting into enormous loss to life and property. According to the Prevention Web statistics, 143039 people were killed and about 150 crore were affected by various disasters in the country during these three decades. The disasters caused huge loss to property and other infrastructures costing more than US $\$ 4800$ crore [5]. Considering the hazard and vulnerability of country towards disasters, it becomes imperative to systematically address various challenges and educate each and vulnerable person for protection and prevention against disasters. One of the biggest challenges in disaster management education in India is its burgeoning population. It becomes difficult to reach out to the larger population in a formal manner, especially to the rural and poorest of the poor.

In terms of Policy development, India has significantly contributed by framing The Disaster Management Act of 2005 . The Act highlights the Pre-Disaster Culture of Prevention, Disaster Risk Assessment \& Reduction, Mitigation (Structural \& NonStructural), and Preparedness. Followed by the Act, The National Policy on Disaster Management has been approved by the Central Government in 2009. The policy has proposed to introduce Disaster Management course in Professional Technical Education. India's 10th Five year plan has emphasized the need for integrating disaster management in the existing education system in India. One of the important initiatives includes disaster management in the curriculum of school and professional education. Empowering the younger generation on the preventive aspects, types of services to be provided in a disaster situation and the need for the human approach is proposed as a part of the curriculum [6]. For imparting formal education in Disaster Management, the Ministry of Human Resource Development (MHRD), India, through Central Board of Secondary Education (CBSE) has introduced Disaster Management subject in grade VIII, IX and X level and for some students in grade XI. All India Council of Technical Education (AICTE) and Council of Architecture (COA) has also introduced Disaster Management as a part of the course curriculum for Engineering and Architecture Graduates and Master students from 2005-2006.

Various Colleges, Universities and Institutions are offering technical and professional courses (Diploma, Degree, Doctorate, Distance and Certificate) in Disaster Management. For imparting informal education in Disaster Management in the country various programs are ongoing for awareness generation; training of communities and volunteers; capacity-building of people and regular mock drills; genger mainstreaming; etc. A representative example of approach adopted for generating awareness is by Folk
Troupes of Uttar Pradesh, India. The aim of the program is to reach out to the rural population and in a way they can best comprehend. The Disaster Management Authority of Uttar Pradesh decided to turn to local media to inform, educate and entertain people. Various training programme of local troupes was organized and puppet shows, magic shows and street plays were performed by these local troupes in different places. These troupes through the medium of traditional folk forms and in the local dialect made people aware of various issues related to disaster management. Various songs were used to convey new, crucial message of safety when dealing with disasters. These songs were composed in local languages such as Hindi, Bhojpuri, Bundelkhandi and Awadhi [7].

\section{Conclusion}

Education plays an important role in shaping our society. It aims at reducing vulnerabilities towards disasters. Educational reforms can promote disaster prevention practice. Disaster safety concept should be an integral part of our daily life. Disaster management education is the most important need for the local government, youngsters, children and communities at large. Knowledge about Disaster Management can be imparted both in formal and informal setting. Informal education in communities is the most flexible of all approaches with respect to setting, audience and timeframe. The focus of informal education is taking advantage of brief moments and encounters to stimulate thinking and engage people in discovery of actions and behaviors to increase safety and resilience. Hence, in addition to formal education, informal education also plays a very significant role in spreading awareness, increase in safety and resilience of the society towards disasters.

\section{Recommendations}

A. A network of people in the community is important and their capacities should be build regularly to implement disaster management, prevention and risk reduction methods. The network should include members from vulnerable community including women, local NGO's, government representatives and media.

B. Informal education system is used at different levels across the country; however duration and time interval for the implementation of these approaches should be carefully introspected. Regular monitoring and performance evaluation of informal approaches should be carried out in order to understand whether it is effective, properly outreached and addressed the need of the community.

C. Funds should be allocated more specifically for imparting informal awareness about disaster management in Primary Health Centers, Community Centers, Schools and other places where people congregate for community activities.

D. During emergency situation, ties and understanding should be formed between Inter-States to share resources. Furthermore, Inter-State exposure visits should be facilitated for learning from the experiences of other States. 
E. Corporate sector should also get involved for dissemination of campaign in both formal and informal setting.

F. Various sets of resources should be developed for sharing of best practices as a source of resource material to be replicated and disseminated in local languages.

\section{References}

1. Guha-Sapir D, Below R, Hoyois (2015) EM-DAT: International Disasters Database. Prod Belgium Universite Catholique de Louvain -Brussels, UK

2. http://www.ifrc.org/Global/Documents/Secretariat/201610/ WDR\%202016-FINAL_web.pdf
3. http://www.ifrc.org/Global/Publications/disasters/reducing risks/302200-Public-awareness-DDR-guide-EN.pdf

4. http://www.ndma.gov.in/en/vulnerability-profile.html

5. http://www.undp.org/content/dam/india/docs/disaster_ management_in_india.pdf

6. http://www.in.undp.org/content/dam/india/docs/towards_a_safer_ india_cbse.pdf

7. http://www.tn.gov.in/tsunami/digitallibrary/ebooks-web/42\%20 Good\%20_Practices.pdf

8. https://www.adb.org/sites/default/files/publication/176899/ewp466.pdf

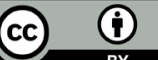

Creative Commons Attribution 4.0 International License

For possible submissions Click Here

\section{Submit Article}

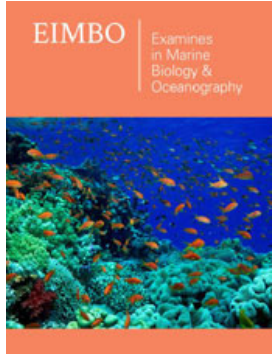

Examines in Marine Biology \& Oceanography

\section{Benefits of Publishing with us}

- High-level peer review and editorial services

- Freely accessible online immediately upon publication

- Authors retain the copyright to their work

- Licensing it under a Creative Commons license

- Visibility through different online platforms 